\section{The principles of vision enumerated}

\section{Oliver Braddick}

A Taxonomy of Visual Processes. By

William R. Uttal. Pp.1,097. ISBN 0-89859-075-2. (Lawrence Erlbaum: 1981.) $\$ 100, £ 50$.

THE stated aim of Uttal's book is to ". . systematize the data base of perceptual psychology into a comprehensive intellectual scheme ...". When the route to this goal runs through 1,100 pages and over 3,000 references, it must involve to a fair degree the exposition of the "data base" itself, and there is here a generous view of its extent, including the discovery of alpha particles, how a cathode ray tube works, the embryology of frog rods and the theory of rainbows. More conventionally, the field of vision is covered from photometry to geometrical illusions. It would not be reasonable to expect a single author to compete in authority over this range with the several multi-author handbooks of similar scope that have appeared in recent years, and Uttal does not do so.

The author shows a propensity for organizing his data base in lists, which rather blunt the reader's appreciation of what might be the relative significance of the information. This culminates in the closing pages in a list of 67 " general principles" from which we may sample No.4:

For millennia, philosophers, scientists, and laymen alike have felt a deep-seated urge to explain the phenomena of perception. . . . No perceptual theory, however, has ever withstood the test of time.

and No.59: "The magnitude of many illusions depends on the orientation of the pattern ...". Several of the lists contain direct contradictions that remain unresolved and without comment by Uttal. The general air is one of abstracting rather than digesting the scientific literature; opportunities for integration are conspicuously missed, for example the use of the temporal modulation transfer function to express data on the visual response to a variety of time-varying stimuli.

But it would be unfair to dwell on Uttal's presentation of the data base, rather than his intention of providing a framework for systematizing it, the "taxonomy" of the title. This taxonomy is one of sequential levels of processing, from Level 0 in the optics of the environment and the eye, to Level 5 which consists of active, attentive manipulations of perceived information which are reserved for another projected book. Most visual scientists use some such idea of levels, albeit informally, as a way of compartmentalizing problems. This is not to say that it is the best principle for the organized presentation of our knowledge of visual perception, and several disadvantages become apparent in Uttal's attempt to do so. One is that there are many phenomena about which we know a good deal, and which are clearly important, but which we cannot partition among levels with any certainty. Ironically, Uttal's own experimental work largely falls into this category, and into a chapter on temporal interactions which he has to present as a frank digression, unassignable to any of his levels on present understanding. In other cases, the organization of the book by levels makes it difficult to evaluate alternative explanations critically. For example, the issue of lateral inhibition versus more global processes in brightness contrast is raised, with vigorous assertions of the importance of the latter, but the plan of the book does not allow them to confront each other. Another consequence is an absence of any functional perspective. The purposes for which vision is used cut right across these levels, so they get little attention here.

A reason for the taxonomic approach becomes apparent in a chapter entitled "Mezzolog: On the Limits of Neuroreductionism"'. Uttal is concerned that much current theorizing, providing speculative neural bases for perceptual phenomena, is premature. Once again, this view is expressed centrally as a list: "Questionable Dogmas", Nos 1-18. Some of the dogmas are general suppositions about the relation between brain activity and perception, and indeed some of these are quite widely believed, at least implicitly. Others (for example No. 15: "Metacontrast results from peripheral lateral inhibitory interactions that diminish the strength of the conducted neural signals") may be specific instances of neuroreductionism, but are not necessarily widely accepted even by those committed to neural reductionist explanations of the phenomenon concerned. Dogmas of these two kinds need rather different kinds of critique, but it is not clear that the difference is appreciated.

The role of the taxonomy is to draw a sharp line between Levels $1-2$, where Uttal offers accounts in terms of interaction of neural signals, and Level 3-4 where the processes are "interpretive", the neural representations involved are not at all understood, and theories are psychological or purely formal.

Uttal's charge of premature reductionism is just in many cases. However the structure and style of his book do not favour a critical marshalling of the arguments on the neural basis of $\$ 65$. specific visual phenomena. Indeed, given the scale of the book, any particular issue is pursued in surprisingly little depth. The temptation of encyclopaedic breadth seems to have deflected the author's purpose of exploring the limits of current neural explanation, which is a pity, for that purpose is a very worthwhile one.

Uttal recounts in his preface that when he "chose to become an explicit generalist rather than a totally dedicated ... laboratory scientist" the reaction of some of his colleagues was such that "some of the experiences encountered were nonsupportive to say the least"'. He defends his role as one of "analysis, criticism, integration and synthesis'. I fear that generalism has caused these activities to be diluted and dispersed to a rather unsatisfying degree.

Oliver Braddick is a Lecturer in Experimental Psychology at the University of Cambridge.

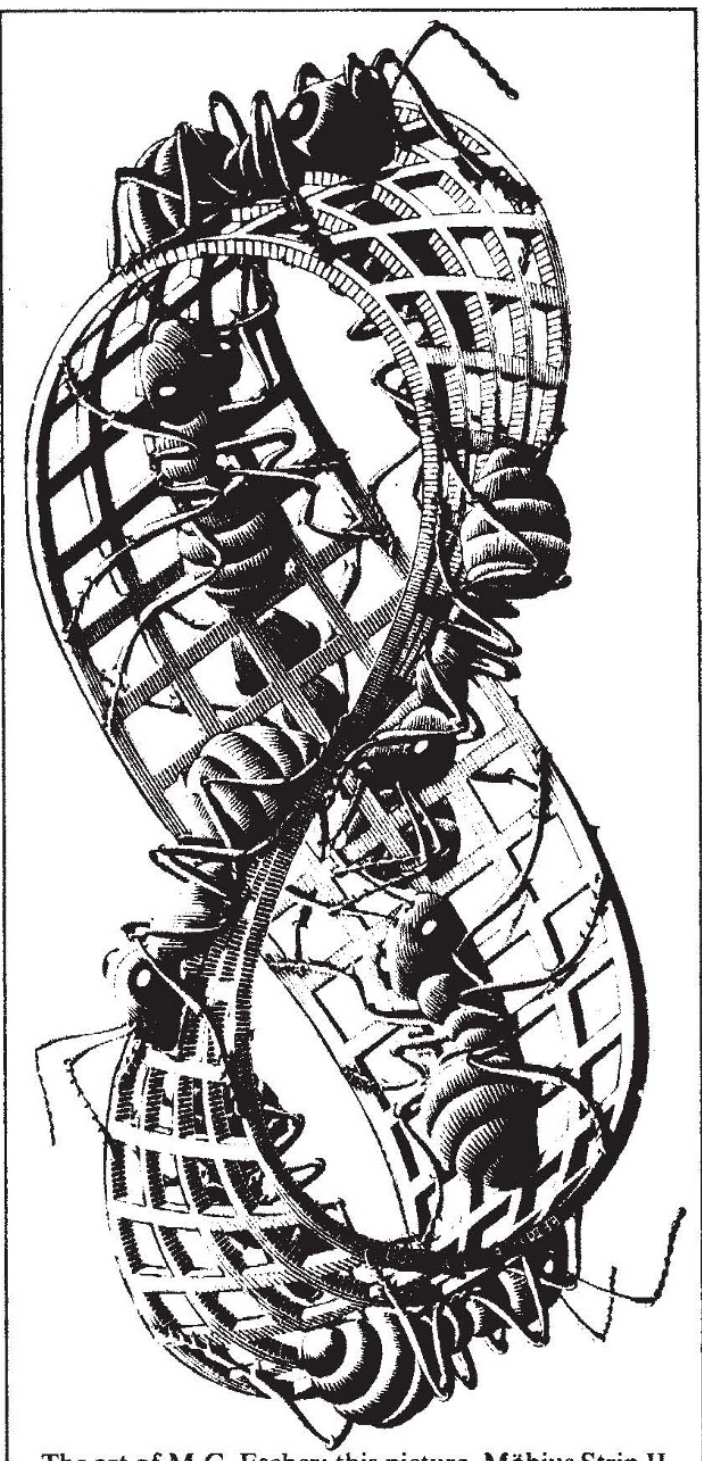

The art of M.C. Escher: this picture, Möbius Strip II (Red Ants), is reproduced from Escher, edited by J.L. Locher and recently published by Thames \& Hudson, London, and Abrams, New York. The book, containing both a copiously illustrated catalogue of Escher's graphic work and a biography, costs $£ 35$, 